University of Nebraska - Lincoln

DigitalCommons@University of Nebraska - Lincoln

\title{
Cloning and expression analysis of hemoglobin genes from maize (Zea mays ssp. mays) and teosinte (Zea mays ssp. parviglumis)
}

\author{
Elena Aréchaga-Ocampo \\ Universidad Nacional Autónoma de México \\ Juan Saenz-Rivera \\ Universidad Nacional Autónoma de México \\ Gautam Sarath \\ University of Nebraska - Lincoln, Gautam.sarath@ars.usda.gov \\ Robert V. Klucas \\ University of Nebraska - Lincoln \\ Raúl Arredondo-Peter \\ Universidad Nacional Autónoma de México, ra@uaem.mx
}

Follow this and additional works at: https://digitalcommons.unl.edu/biochemistrysarath

Part of the Biochemistry, Biophysics, and Structural Biology Commons

Aréchaga-Ocampo, Elena; Saenz-Rivera, Juan; Sarath, Gautam; Klucas, Robert V.; and Arredondo-Peter, Raúl, "Cloning and expression analysis of hemoglobin genes from maize (Zea mays ssp. mays) and teosinte (Zea mays ssp. parviglumis)" (2001). Gautam Sarath Publications. 9.

https://digitalcommons.unl.edu/biochemistrysarath/9

This Article is brought to you for free and open access by the Biochemistry, Department of at DigitalCommons@University of Nebraska - Lincoln. It has been accepted for inclusion in Gautam Sarath Publications by an authorized administrator of DigitalCommons@University of Nebraska - Lincoln. 


\title{
Cloning and expression analysis of hemoglobin genes from maize (Zea mays ssp. mays) and teosinte (Zea mays ssp. parviglumis)
}

\author{
Elena Aréchaga-Ocampo, ${ }^{\mathrm{a}, 1}$ Juan Saenz-Rivera, ${ }^{\mathrm{a}, 1}$ Gautam Sarath, ${ }^{\mathrm{b}}$ \\ Robert V. Klucas, ${ }^{\mathrm{b}}$ and Raúl Arredondo-Peter ${ }^{\mathrm{a}}$ \\ a Centro de Investigación sobre Fijación de Nitrógeno, Universidad Nacional Autónoma de México, \\ Apartado Postal 565-A, 62210 Cuernavaca, Morelos, Mexico \\ ${ }^{\mathrm{b}}$ Department of Biochemistry, George W. Beadle Center, University of Nebraska-Lincoln, Lincoln, NE 68588-0664, USA \\ ${ }^{1}$ The first two authors contributed equally to this work. \\ Corresponding author - R. Arredondo-Peter, fax 52 7-3-17-55-81, email ra@cifn.unam.mx
}

\begin{abstract}
With the exception of barley and rice, little is known about the existence of hemoglobins (Hbs) in cereals. This work reports the cloning and analysis of $h b$ genes from maize (Zea mays ssp. mays) and teosinte (Zea mays ssp. parviglumis). Coding sequences of maize and teosinte $h b$ genes ( $h b m$ and $h b t$, respectively) are highly similar to each other and are interrupted by three introns located at identical positions as other plant $h b$ genes. Sequences of predicted Hbm and Hbt proteins are identical. The hydropathic profile of $\mathrm{Hbm}$ and $\mathrm{Hbt}$ is highly similar to that of rice $\mathrm{Hb1}$, suggesting that $\mathrm{Hbm}, \mathrm{Hbt}$ and $\mathrm{Hb1}$ have the same tertiary structure and biochemical properties. Expression analysis showed that low levels of $\mathrm{Hb}$ transcripts, but considerable levels of $\mathrm{Hb}$ proteins exist in maize embryonic organs. No $\mathrm{Hb}$ transcripts and proteins were detected in teosinte embryonic organs. Low levels of $\mathrm{Hb}$ proteins, but no $\mathrm{Hb}$ transcripts, were detected in maize and teosinte vegetative organs. These observations suggest that the regulation of $h b$ genes is different in maize and teosinte embryonic organs, and that the expression of $h b$ genes is down- or up-regulated in maize and teosinte, respectively, from germination to vegetative growing.
\end{abstract}

Keywords: Gene expression, Hemoglobin, Maize, Non-symbiotic, Teosinte, Zea

Abbreviations: $\mathrm{Hb}$, hemoglobin; $\mathrm{Hbm}$, maize $\mathrm{Hb}$; $\mathrm{Hbt}$, teosinte $\mathrm{Hb}$

\section{Introduction}

Hemoglobins (Hbs) are heme proteins that have been detected in all phyla, and function by binding and transporting oxygen and other gaseous ligands [1-3]. In plants, non-symbiotic Hbs have been detected in organs of vascular and non-vascular species; however, the function of this group of proteins is still not known [4, 5]. Among flowering plants, genes coding for non-symbiotic $\mathrm{Hbs}$ were cloned from dicot and monocot species. In dicots, non-symbiotic Hbs were first detected in root nodules and roots of Parasponia [6], and roots of Trema tomentosa [7], and more recently non-symbiotic $h b$ genes were cloned from a number of dicot plants, including soybean [8] and Arabidopsis [9]. Apparently, the expression of non-symbiotic $h b$ genes varies significantly, and the highest levels of expression were detected in metabolically active or stressed organs. For example, high- est levels of non-symbiotic $\mathrm{Hb}$ transcripts were detected in soybean stems [8], which are metabolically active organs. In Arabidopsis, two $h b$ genes were cloned and analyzed: $a h b 1$ gene is expressed in roots and rosette leaves but overexpressed under hypoxic conditions, whereas $a h b 2$ gene is expressed at low levels in rosette leaves but overexpressed at low temperatures [9].

In monocots, genes coding for non-symbiotic $\mathrm{Hbs}$ were first cloned from barley [10] and subsequently from rice [11], but Southern blot analysis using a heterologous $h b$ probe from barley showed that $h b$ genes also exist in a number of cereals, such as maize, rye and wheat [10]. In barley, a single copy of the non-symbiotic $h b$ gene exists, which is expressed in plant roots, and overexpressed in roots from plants growing in microaerobiosis. In rice four copies of the $h b$ gene exist, and different promoters were identified suggesting that rice $h b$ genes are regulated by different trans-acting factors 
(Lira-Ruan et al., submitted; [11]).

A cDNA with sequence similarity to non-symbiotic $\mathrm{Hbs}$ was cloned from stressed maize organs, and the full sequence was subsequently deposited in the GenBank database (accession No. AF236080). Despite the above entry, no work has been reported on maize Hbs. Maize is an important crop and a good model to analyze the role of non-symbiotic $\mathrm{Hbs}$ in plants because much information has been published concerning maize physiology, biochemistry and genetics. Moreover, the origin of maize is well documented and it has been postulated that the contemporary maize evolved from the domestication of teosinte [12-16]. Thus, the evolutive relationship between maize and teosinte is an interesting model to perform analyses of plant $\mathrm{Hbs}$. In this work we report the cloning and analysis of $h b$ genes from maize and teosinte.

\section{Materials and methods}

\subsection{Seed germination and plant growing}

Maize (Zea mays ssp. mays) seeds were obtained commercially, and teosinte (Zea mays ssp. parviglumis) seeds were either provided by Dr. Mark J. Millard (Iowa State University, USA) or collected at Teloloapan (Guerrero State) in the Balsas Region, México. Maize and teosinte seeds were germinated for 5-7 days in paper towels imbibed in water. Embryonic organs, such as coleoptiles, seminal roots and embryos, were collected from germinated seeds. To avoid any contamination from the endosperm, embryos were carefully detached from the cotyledon using a microspatula and, if necessary, endosperm remains were removed using a razor blade. Organs were immediately frozen in liquid nitrogen and stored at $-80^{\circ} \mathrm{C}$ until used. Germinated seeds were also planted in pots containing vermiculite and then grown in a greenhouse at $22^{\circ} \mathrm{C}$ with light/dark periods of $12 \mathrm{~h} / 12 \mathrm{~h}$. Plants were watered with tap water every third day and with nutrient solution [17] every sixth day. Young and mature plants were grown for 2 or 16 weeks after germination, respectively, and roots and leaves were collected as above and stored at $-80^{\circ} \mathrm{C}$ until used.

\subsection{Total DNA and RNA isolation}

Total DNA was isolated from 1-3 g of roots or leaves using a modification of the hexadecyltrimethylammonium bromide method [18]. Total RNA was isolated from 100 $\mathrm{mg}$ of frozen tissues using the Tryzol reagent (Gibco BRL), and poly(A) ${ }^{+}$RNA was isolated using a QuickPrep mRNA purification kit (Pharmacia-Amersham) following the instructions of the manufacturers. DNA and total RNA and poly $(\mathrm{A})^{+}$RNA were quantitated by spec- trophotometry assuming $A_{260}=50$ or $40 \mu \mathrm{g} / \mathrm{ml}$ for DNA and RNA, respectively [19].

\subsection{Primers and $P C R$ amplification}

PCR primers were designed to amplify the maize and teosinte $h b$ genes ( $h b m$ and $h b t$, respectively) using sequences from the Start and Stop codons of the maize $\mathrm{Hb}$ cDNA (GenBank accession No. AF236080). Oligonucleotide sequences were 5'-ATGGCACTCGCGGAGGCCGAC-3' and 5'-CTAGGCATCGGGCTTCAT-3' for the sense (Maize $\mathrm{Hb} / \mathrm{ATG}$ ) and antisense (Maize $\mathrm{Hb}$ / TAG) primers, respectively. Total plant DNA $(\sim 0.5 \mu \mathrm{g})$ was used as template for PCR amplification. PCR components and concentrations were: $0.5 \mu \mathrm{M}$ of each sense and antisense primer, $200 \mu \mathrm{M}$ of each dNTP and $0.5 \mathrm{U}$ of Taq DNA polymerase (Gibco BRL) in $1 \times \mathrm{PCR}$ buffer containing $1.5 \mathrm{mM} \mathrm{MgCl}_{2}$. PCR was done in a final volume of $25 \mu \mathrm{l}$ using a thermal cycler (Progene). Amplification was carried out for 35 cycles at $60^{\circ} \mathrm{C}$ for annealing, and PCR products were detected in a $1.4 \%(\mathrm{w} / \mathrm{v})$ agarose gel after staining with ethidium bromide.

\subsection{Cloning of hbm and hbt genes}

PCR products were isolated from the agarose gel using the Genclean kit (Bio 101) and then cloned into the vector pCR2.1 (Invitrogen) following standard protocols [19]. Cloned fragments were fully sequenced in both directions at the DNA Sequencing Facility of the University of Nebraska-Lincoln, USA, and DNA sequences were compared with sequences deposited in the GenBank database using the BLAST program [20]. Additional computer analyses were performed using the GCG package (Genetics Computer Group).

\subsection{Detection of Hbm and Hbt transcripts in plant organs}

Detection of $\mathrm{Hb}$ transcripts in plant organs was performed by RT-PCR [21] using a RNA-PCR kit (Cetus or Gibco BRL). Reverse transcription was done using $1 \mu \mathrm{g}$ of total RNA or $45 \mathrm{ng}$ of poly $(\mathrm{A})^{+} \mathrm{RNA}$ as the template for embryonic and vegetative organs, respectively, and oligo $\mathrm{d}(\mathrm{T})_{16}$ as primer following the manufacturer's protocol. PCR amplification was performed with the primers Maize Hb/ATG and Maize Hb/TAG that had been used for the amplification of $h b m$ and $h b t$ and the same conditions described above, but for 40 cycles. For a positive control, ubiquitin transcripts were amplified using the primers Ubi sense (5'-GTTCTCCGCCTCAGGGGAGGC-3') and Ubi antisense (5'-GCTTAAATGAACCATGGCTTA-3') from a maize ubiquitin cDNA (GenBank accession No. U29158). PCR products were detected in a $1.4 \%(\mathrm{w} / \mathrm{v})$ agarose gel after staining with ethidium bromide. 


\subsection{Purification of recombinant rice $\mathrm{Hb} 1$ and generation of anti-rice $\mathrm{Hb} 1$ antibodies}

Purification of recombinant rice $\mathrm{Hb} 1$ from transgenic Escherichia coli $\mathrm{pEMBL18}{ }^{+} / \mathrm{rHb} 1$ [11] was performed essentially as described by Arredondo-Peter et al. [22]. Pure rice $\mathrm{Hb} 1$ was used to generate polyclonal anti-rice $\mathrm{Hb} 1$ antibodies in rabbits by the Monoclonal Antibody Core Facility of the University of Nebraska-Lincoln, USA.

\subsection{Western blot analysis of maize and teosinte organs}

Plant organs (0.5-1 g) were homogenized with liquid nitrogen, and the homogenate was resuspended in 2 vols. of extraction buffer ( $20 \mathrm{mM}$ Tris- $\mathrm{HCl}, \mathrm{pH} 8$, containing $1 \mathrm{mM}$ phenylmethylsulfoxide fluoride). The resulting solution was centrifuged at $13000 \times g$ at $4^{\circ} \mathrm{C}$, and the supernatant was used for determination of total proteins by a dye-binding assay (Sigma-Aldrich) using bovine serum albumin as standard. To adjust to a protein concentration of 1-2 $\mu \mathrm{g} / \mu \mathrm{l}$, samples were concentrated by centrifugation using centrifugal concentrators (Centricon). Samples consisting of fresh extracts ( $40 \mu \mathrm{g}$ of total soluble proteins/lane) were subjected to electrophoresis in a $15 \%(\mathrm{w} / \mathrm{v})$ sodium dodecyl sulfate-polyacrylamide gel, and then transferred in transfer buffer $(25 \mathrm{mM}$ Tris$\mathrm{HCl}, \mathrm{pH}$ 8.0, $192 \mathrm{mM}$ glycine, 20\% (v/v) methanol) to a Hybond C-extra nitrocellulose membrane (PharmaciaAmersham) at $4^{\circ} \mathrm{C}$ overnight.

Western blotting was performed at least in triplicate following standard protocols [23]. Briefly, membranes were blocked by incubation with $3 \%(\mathrm{w} / \mathrm{v})$ nonfat dry milk in TBS buffer (100 mM Tris-HCl, $\mathrm{pH} 8.0$, $150 \mathrm{mM} \mathrm{NaCl}$ ) containing $0.05 \%(\mathrm{v} / \mathrm{v})$ Tween 20 . Protein blots were incubated with a $1 / 5000$ dilution of the anti-rice $\mathrm{Hb} 1$ antibodies for $1 \mathrm{~h}$ at room temperature. Blots were washed with TBS-Tween and then incubated with a 1/3000 dilution of the anti-rabbit IgG conjugated with alkaline phosphatase (Roche) for $1 \mathrm{~h}$ at room temperature. After washing with TBS-Tween, blots were developed using the chromogenic mix nitroblue tetrazolium/5-bromo-4-chloroindolyl phosphate (Roche).

\section{Results and discussion}

\subsection{Cloning and characterization of hbm and hbt genes}

When total DNA from maize and teosinte was used as the template with primers designed for the maize $\mathrm{Hb}$ cDNA, two PCR products of approx. 650 and $880 \mathrm{bp}$ were obtained (Figure 1). These PCR products were purified, cloned and sequenced, and the sequences were compared with sequences deposited in the GenBank database. The sequence of the smaller fragment (650 bp) showed no similarity with $\mathrm{Hbs}$ and was a non-specific amplification. The sequence of the larger fragment (880 $\mathrm{bp)}$ from maize (Figure 1A) and teosinte (Figure 1B)

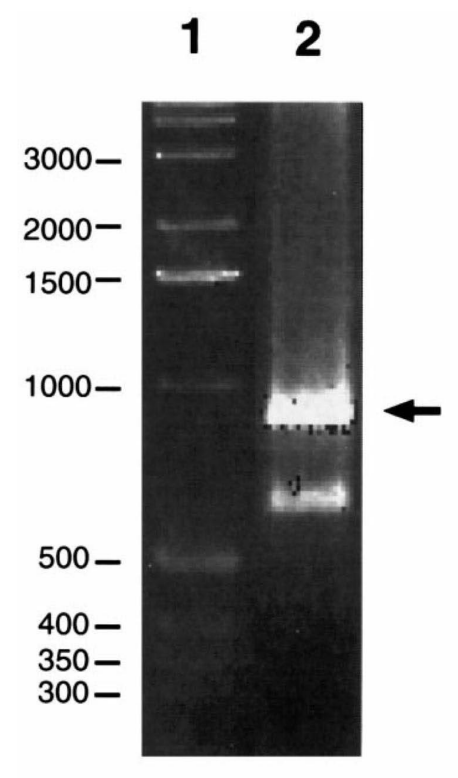

(A)

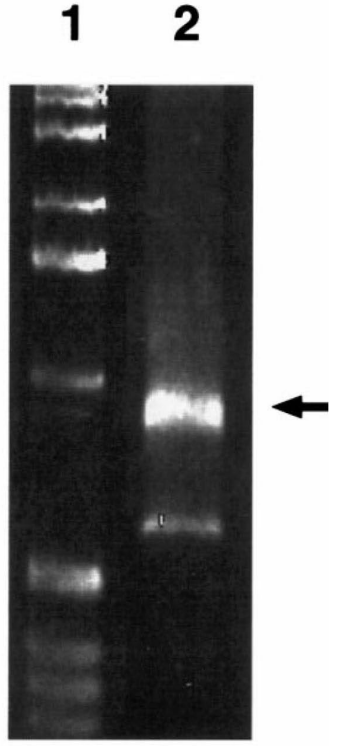

(B)
Figure 1. Amplification of maize (A) and teosinte (B) $h b$ genes by PCR using the primers Maize $\mathrm{Hb} / \mathrm{ATG}$ and Maize $\mathrm{Hb} /$ TAG. Samples were subjected to electrophoresis in a $1.4 \%$ $(\mathrm{w} / \mathrm{v})$ agarose gel and stained with ethidium bromide. Lane 1, $1 \mathrm{~kb}$ ladder; lane 2, total PCR reaction. Arrows show the 880 bp fragment corresponding to maize and teosinte $h b$ genes. Molecular size markers are shown in bp.

was identical or very similar to the maize $\mathrm{Hb}$ cDNA sequence, respectively, indicating that these fragments corresponded to the $h b m$ and $h b t$ genes.

The $h b m$ and $h b t$ sequences were compared to the maize $\mathrm{Hb}$ cDNA to identify exon and intron (IVS) sequences. Both hbm and hbt genes have four exons and three introns (Figure 2) located at identical positions as all of the known plant $h b$ genes $[11,24,25]$. However, the nucleotide sequence at the 3 ' splice site of the first intron and $5^{\prime}$ splice site of the third intron was unusual in $\mathrm{hbm}$ and $h b t$ (agGG and AGgc, respectively) (Figure 2) compared to those sequences from Parasponia [25] and rice [11] $h b$ genes (agGA and AGgt, respectively). Sequence comparison between $\mathrm{hbm}$ and $h b t$ showed that exons were highly conserved ( $\sim 99 \%$ similar), but intron sequences were rather variable (similarity values were 68 , 95 and $83 \%$ for IVS-I, IVS-II and IVS-III, respectively).

Maize and teosinte $h b$ genes code for predicted proteins of 164 amino acid residues in length (Figure 3), with a calculated molecular mass of $18.3 \mathrm{kDa}$. Sequence comparison showed that the predicted $\mathrm{Hbm}$ and $\mathrm{Hbt}$ proteins are identical to each other. $\mathrm{Hbm}$ and $\mathrm{Hbt}$ contain distal (H76) and proximal (H111) His residues, as well as the P51, F57, F81, and F121 that are highly conserved in plant $\mathrm{Hbs}$ [24]. Also, $\mathrm{Hbm}$ and Hbt contain a single Cys residue, C85, that is conserved in non-symbiotic Hbs (Figure 3) [11]. 


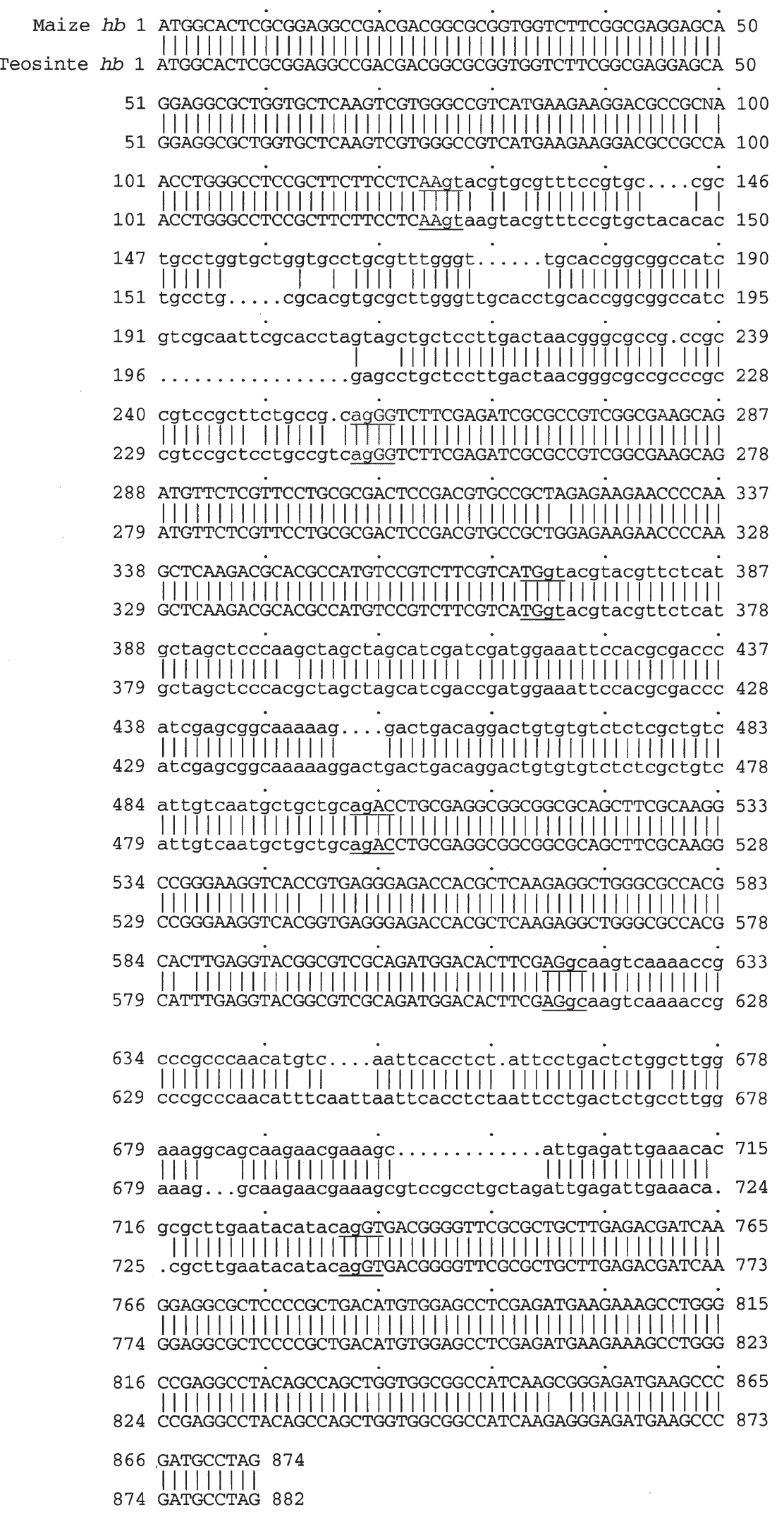

Figure 2. Sequence alignment of maize and teosinte $h b$ genes. Coding (exon) and non-coding (intron) sequences are shown in upper and lowercase letters, respectively. Vertical bars show identical bases in both sequences. Dots correspond to indels (insertion/ deletion). Sequences flanking the exon/intron boundaries are underlined. $\mathrm{N}$ at position 99 of maize $h b$ gene corresponds to $\mathrm{C}$ or A. Sequences were aligned using the PileUp routine of the GCG program. Maize and teosinte $h b$ gene sequences were deposited in the GenBank database under accession Nos. AY005818 and AF291052, respectively. 


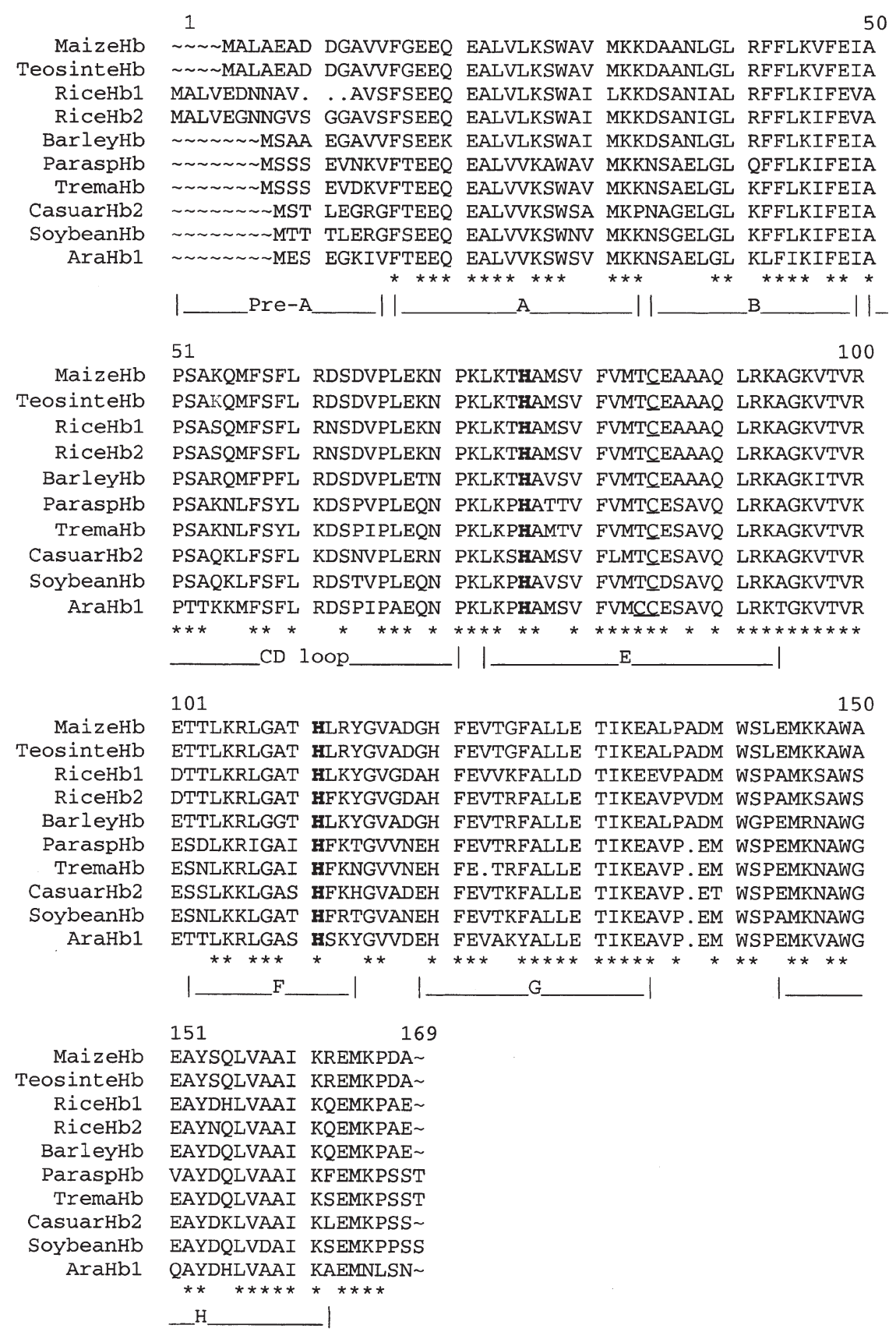

Figure 3. Sequence alignment of cereal and selected non-symbiotic Hbs. Distal (H76) and proximal (H111) His residues are shown in bold type, and Cys residues are underlined. Asterisks show the most conserved residues. Helix regions are calculated from the structure of rice $\mathrm{Hb} 1$ [26]. Amino acid sequences were obtained from the GenBank database using the following accession Nos.: U76030 (rice Hb1), U76031 (rice Hb2), U01228 (barley Hb), M36509 (Parasponia andersonii Hb), Y00296 (Trema tomentosa Hb), X53950 (Casuarina glauca Hb2), U47143 (soybean $\mathrm{Hb}$ ) and U94998 (Arabidopsis thaliana Hb1). Alignment of sequences was done using the PileUp routine of the GCG program.

Computer analysis showed that the hydropathy profile of $\mathrm{Hbm}$ and $\mathrm{Hbt}$ is highly similar to that of recombinant rice $\mathrm{Hb} 1$ (Figure 4). The tertiary structure of rice $\mathrm{Hb} 1$ was elucidated recently [26], and it was shown that rice $\mathrm{Hb} 1$ is a dimer when the concentration is approx. 0.8 $\mathrm{mM}$ [27]. Thus, the above observation suggests that the tertiary structure of $\mathrm{Hbm}$ and $\mathrm{Hbt}$ is very similar to that of rice $\mathrm{Hb} 1$. Moreover, it has been proposed that resi- dues I/V49, S52, E122, V123 and F126 form the dimer interface of rice $\mathrm{Hb} 1$ and other non-symbiotic $\mathrm{Hbs}$ [26]. These residues are also conserved in $\mathrm{Hbm}$ and $\mathrm{Hbt}$ (Figure 3), which strongly suggests that $\mathrm{Hbm}$ and $\mathrm{Hbt}$ can also form dimers. Thus, we predict that the biochemical properties of $\mathrm{Hbm}$ and $\mathrm{Hbt}$ are the same to those reported for the rice $\mathrm{Hb} 1[11,26,27]$, i.e. $\mathrm{Hbm}$ and $\mathrm{Hbt}$ have a very high affinity for oxygen. 


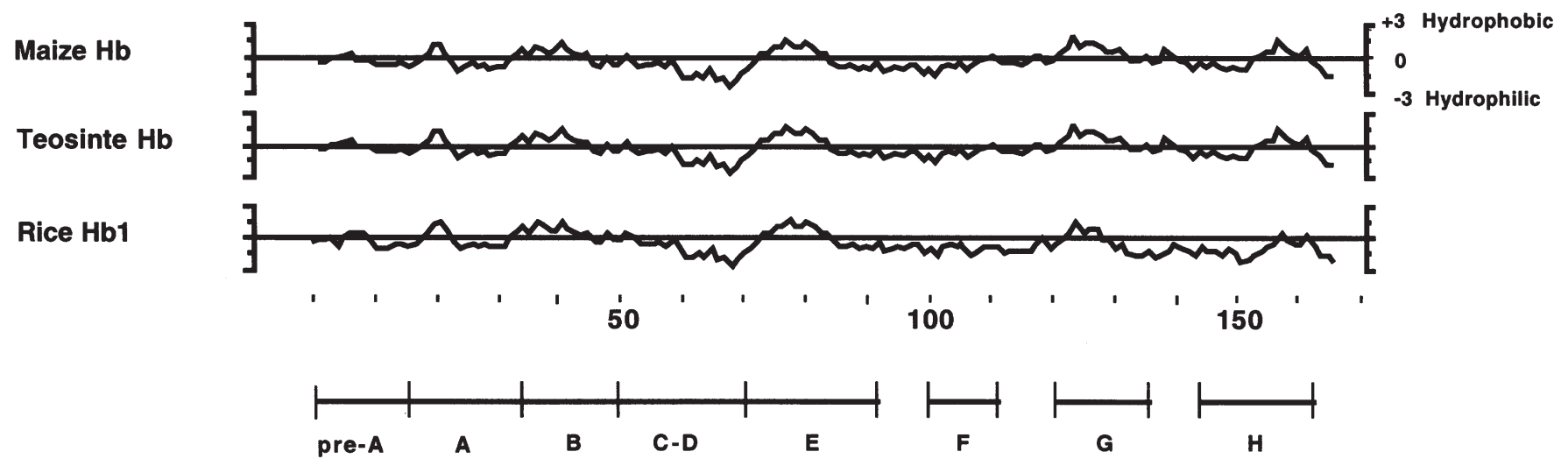

Figure 4. Hydropathy profiles of $\mathrm{Hbm}, \mathrm{Hbt}$ and rice $\mathrm{Hb} 1$. Helix regions are calculated from the structure of rice $\mathrm{Hb} 1$ [26]. Hydropathy analysis was performed with the Peplot routine of the GCG program.

\subsection{Expression analysis of hbm and hbt genes in plant organs}

Non-symbiotic Hbs have been detected in plant organs by Northern blot [8], RT-PCR [11] and Western blot [28, 29]. In this work we analyzed the expression of $h \mathrm{bm}$ and hbt genes in plant organs by evaluating the levels of $\mathrm{Hb}$ transcripts and proteins by RT-PCR and Western blot, respectively.

To determine the levels of $\mathrm{Hb}$ transcripts in maize and teosinte organs, total and poly $(\mathrm{A})^{+}$RNA were isolated from embryonic (coleoptiles, seminal roots and embryos) and vegetative (young and mature leaves and roots) organs, and then subjected to PCR using primers for $\mathrm{Hbm}$ cDNA (above). Low levels of amplification products of the expected size (498 bp) were detected in maize coleoptiles, seminal roots and embryos (Figure $5 \mathrm{~A})$, indicating that $\mathrm{hbm}$ expresses in maize embryonic organs. However, no amplification products were detected in teosinte embryonic (Figure 5B) and maize and teosinte vegetative (Figure 6) organs. Thus, to explore the possibility that the amount of $\mathrm{Hb}$ transcripts was below the detection limit in the above organs an $(10 \mu \mathrm{l})$ aliquot of the RT-PCR reaction was subjected to a re-PCR for 40 additional cycles; however, no $\mathrm{Hb}$ transcripts were detected after re-PCR.

Maize and teosinte $h b$ genes code for proteins with a predicted molecular mass of $18.3 \mathrm{kDa}$, which is nearly identical to the molecular mass of recombinant rice $\mathrm{Hb} 1$ $(18.4 \mathrm{kDa})$ [11]. Our previous analysis by Western blot showed that soluble extracts of maize and teosinte organs contain proteins that comigrate with rice $\mathrm{Hb} 1$, and that specifically cross-react with anti-rice $\mathrm{Hb} 1$ antibodies (not shown), suggesting that these proteins were maize and teosinte $\mathrm{Hbs}$. To determine the level of $\mathrm{Hb}$ proteins in maize and teosinte organs the same amount of fresh plant soluble extracts were Western blotted with antirice $\mathrm{Hb} 1$ antibodies. Results showed that high levels of $\mathrm{Hbm}$ protein exist in maize embryonic organs (Figure $5 \mathrm{~A}$ ), and that the highest levels of $\mathrm{Hbm}$ were detected in seminal roots and embryos, and the lowest in coleoptiles. Hbm proteins were also detected in maize vegetative organs (young and mature leaves and roots) (Figure 6A), but the $\mathrm{Hb}$ levels were considerably lower than those detected in embryonic organs. No differences were observed between $\mathrm{Hbm}$ levels from leaves and roots, or young and mature organs. In contrast to maize, Hbt proteins were not detected in teosinte embryonic organs (Figure 5B), which is consistent with the

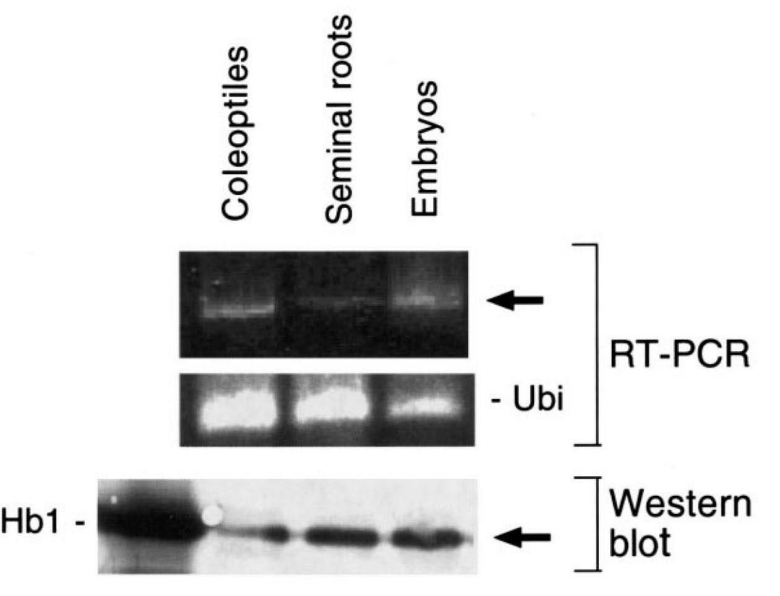

(A)

(B)

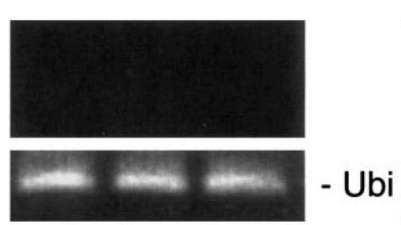

RT-PCR

$\mathrm{Hb} 1$

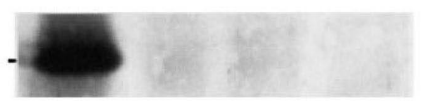

Western blot

Figure 5. Expression of $h b$ genes in embryonic organs from maize (A) and teosinte (B). Arrows show the $\mathrm{Hb}$ transcripts (498 bp) and proteins (18.3 kDa) detected by RT-PCR and Western blot, respectively. Maize ubiquitin (Ubi) (500 bp) and rice $\mathrm{Hb} 1$ ( $\mathrm{Hb} 1)(18.4 \mathrm{kDa})$ were used as controls for RT-PCR and Western blot, respectively. These results are representative of at least three replicates. 


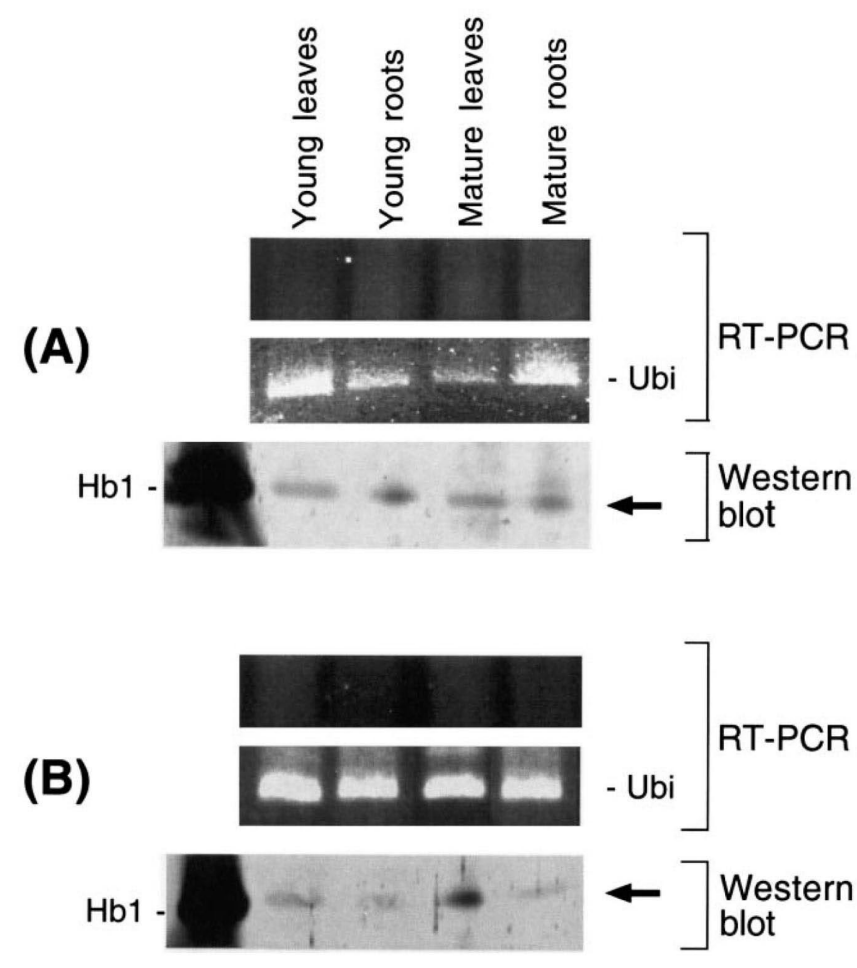

Figure 6. Expression of $h b$ genes in vegetative organs from maize (A) and teosinte (B). Arrows show the $\mathrm{Hb}$ proteins $(18.3$ $\mathrm{kDa}$ ) detected by Western blot. Maize ubiquitin (Ubi) (500 bp) and rice $\mathrm{Hb} 1$ (Hb1) (18.4 kDa) were used as controls for RT-PCR and Western blot, respectively. These results are representative of at least three replicates.

inability to detect $\mathrm{Hbt}$ transcripts by RT-PCR and rePCR (above). However, low levels of Hbt proteins were detected in teosinte young and mature leaves and roots (Figure 6B); apparently, Hbt levels were higher in leaves than in roots from young and mature plants.

The above observations suggest that $h b$ genes are differently expressed in maize and teosinte organs. In maize embryonic organs $h b$ genes express and transcripts are translated at considerable levels of Hbm protein; in contrast, in teosinte embryonic organs apparently $h b$ genes are shut down as no Hbt transcripts and proteins were detected. These results were surprising given the relatedness of teosinte to maize, and the existence of Hbs in seeds of other cereals [10, 29]. However, it is still possible that Hbt could be below detection limits, or that $h b t$ gene has a different type of regulation. In vegetative organs from maize and teosinte no $\mathrm{Hb}$ transcripts were detected, but low levels of $\mathrm{Hb}$ proteins were detected. This observation suggests that in vegetative organs $h b m$ and $h b t$ express at very low levels (below the detection limit) resulting in low abundance of $\mathrm{Hbm}$ and $\mathrm{Hbt}$ transcripts, which are translated in detectable levels of proteins. Therefore, the results obtained in this work suggest that the expression of $h b$ genes is down- or upregulated in maize and teosinte, respectively, from germination to vegetative growing.

\section{Conclusions}

The results presented above show that $h b$ genes from maize and teosinte are highly conserved and code for identical $\mathrm{Hb}$ proteins. This suggests that the domestication of teosinte to maize did not substantially affect the evolution of $\mathrm{Hbs}$ in these plants. The function of non-symbiotic Hbs in plants is not known [4,30], but the existence of $\mathrm{Hbs}$ in specific tissues of plant organs suggests that non-symbiotic $\mathrm{Hbs}$ play specialized rather than housekeeping functions (Ross et al., submitted). In this work we showed that the $h b$ genes are expressed and $\mathrm{Hb}$ proteins are synthesized in maize and teosinte organs. However, apparently the regulation of $h b$ genes is different in maize and teosinte seeds suggesting that $\mathrm{Hbm}$ and $\mathrm{Hbt}$ play different roles in the plant embryonic organs. Taylor et al. [10] and Lira-Ruan et al. [29] detected Hbs in germinating seeds from barley and rice, respectively, and it was postulated that $\mathrm{Hbs}$ play a role in germination, i.e. by providing $\mathrm{O}_{2}$ to sustain an active metabolism. However, no $\mathrm{Hbs}$ were detected in germinating seeds from teosinte suggesting that these proteins are not essential for germination in this plant. Also, as judged by the level of sensitivity of the procedures used in this work, the expression of $h b$ genes in maize and teosinte vegetative organs is extremely low but high enough for the synthesis of detectable $\mathrm{Hb}$ proteins. Level of $\mathrm{Hb}$ proteins in maize and teosinte vegetative organs were comparable, thus it is likely that $\mathrm{Hbs}$ have a similar function in leaves and roots from maize and teosinte.

\section{Acknowledgments}

The authors wish to express their gratitude to Drs. Mark J. Millard (Iowa State University, USA) and Cesáreo Catalán Everad (University of Guerrero, México) for providing the teosinte seeds. To Dr. Robert Hill (University of Manitoba, Canada) for providing information about the maize $\mathrm{Hb}$ cDNA clone. To three anonymous reviewers for helpful suggestions. This work was partially funded by Consejo Nacional de Ciencia y Tecnología $(25229 \mathrm{~N})$ and DGAPA/PAPIIT-UNAM (IN202399), Mexico.

\section{References}

1. A.F. Riggs, Aspects of the origin and evolution of non-vertebrate hemoglobins. Am. Zool. 31 (1991), pp. 535-545.

2. S.N. Vinogradov, D.A. Waltz, B. Pohajdak, L. Moens, O.H. Kapp, T. Suzuki and C.N.A. Trotman, Adventitious variability? The amino acid sequences of nonvertebrate globins. Comp. Biochem. Physiol. 106B (1993), pp. 1-26.

3. R. Weber and S.N. Vinogradov, Nonvertebrate hemoglobins: functions and molecular adaptations. Physiol. Rev. 81 (2001), pp. 569-628. 
4. R. Arredondo-Peter, M.S. Hargrove, J.F. Moran, G. Sarath and R.V. Klucas, Plant hemoglobins. Plant Physiol. 118 (1998), pp. 1121-1126.

5. R. Arredondo-Peter, M. Ramírez, G. Sarath and R.V. Klucas, Sequence analysis of an ancient hemoglobin cDNA isolated from the moss Physcomitrella patens (accession No. AF218049). Plant Physiol. 122 (2000), p. 1457.

6. C.A. Appleby, J.D. Tjepkema and M.J. Trinick, Hemoglobin in a nonleguminous plant Parasponia: possible genetic origin and function in nitrogen fixation. Science 220 (1983), pp. 951-953.

7. D. Bogusz, C.A. Appleby, J. Landsmann, E.S. Dennis, M.J. Trinick and W.J. Peacock, Functioning of haemoglobin genes in a non-nodulating plant. Nature 331 (1988), pp. 178-180.

8. C.R. Andersson, E.O. Jensen, D.J. Llewellyn, E.S. Dennis and W.J. Peacock, A new hemoglobin gene from soybean: a role for hemoglobin in all plants. Proc. Natl. Acad. Sci. USA 93 (1996), pp. 5682-5687.

9. B. Trevaskis, R.A. Watts, S.R. Andersson, D.J. Llewellyn, M.S. Hargrove, J.S. Olson, E.S. Dennis and W.J. Peacock, Two hemoglobin genes in Arabidopsis thaliana: the evolutionary origins of leghemoglobins. Proc. Natl. Acad. Sci. USA 94 (1997), pp. 12230-12234.

10. E.R. Taylor, X.Z. Nie, A.W. MacGregor and R.D. Hill, A cereal haemoglobin gene is expressed in seed and root tissues under anaerobic conditions. Plant Mol. Biol. 24 (1994), pp. 853-862.

11. R. Arredondo-Peter, M.S. Hargrove, G. Sarath, J.F. Moran, J. Lohrman, J.S. Olson and R.V. Klucas, Rice hemoglobins: gene cloning, analysis and oxygen-binding kinetics of a recombinant protein synthesized in Escherichia coli. Plant Physiol. 115 (1997), pp. 1259-1266.

12. B.F. Benz, Archaeological evidence of teosinte domestication from Guilá Naquitz, Oaxaca. Proc. Natl. Acad. Sci. USA 98 (2001), pp. 2104-2106.

13. J. Doebley and A. Stec, Genetic analysis of the morphological differences between maize and teosinte. Genetics 129 (1991), pp. 285-295.

14. J. Doebley, A. Stec and C. Gustus, teosinte branched1 and the origin of maize: evidence for epistasis and the evolution of dominance. Genetics 141 (1995), pp. 333-346.

15. H.H. Iltis, Morphological and Systematic Studies of the Male Inflorescence of teosinte, University of Wisconsin Herbarium, Madison, WI, 1974.

16. D.R. Piperno and K.V. Flannery, The earliest archaeological maize (Zea mays L.) from highland Mexico: new accelerator mass spectrometry dates and their implications. Proc. Natl. Acad. Sci. USA 98 (2001), pp. 2101-2103.

17. M. Becana, M.L. Salin, L. Ji and R.V. Klucas, Flavin-mediated reduction of ferric leghemoglobin from soybean nodules. Planta 183 (1991), pp. 575-583.

18. J. Crose and B. Amorese, Isolation of plant DNA from fresh tissue. Focus 9 (1978), pp. 3-6.

19. F.M. Ausubel, R. Brent, R.E. Kingston, D.D. Moore, J.G. Seidman, J.A. Smith, K. Struhl, Current Protocols in Molecular Biology, Wiley, New York, 1995.

20. S.F. Altschul, W. Gish, W. Miller, E.W. Myers and D.J. Lipman, Basic local alignment search tool. J. Mol. Biol. 215 (1990), pp. 403-410. 21. A.M. Wang, M.V. Doyle and D.F. Mark, Quantitation of mRNA by the polymerase chain reaction. Proc. Natl. Acad. Sci. USA 86 (1989), pp. 9717-9721.

22. R. Arredondo-Peter, J.F. Moran, G. Sarath, P. Luan and R.V. Klucas, Molecular cloning of the cowpea (Vigna unguiculata) leghemoglobin II gene and expression of its cDNA in Escherichia coli; purification and characterization of the recombinant protein. Plant Physiol. 114 (1997), pp. 493-500.

23. G. Sarath, F.W. Wagner, Immunological detection of nitrogenase, in: H.F. Linskens, J.F. Jackson (Eds.), Modern Methods of Plant Analysis, Springer-Verlag, Berlin, 1989, pp. 227-239.

24. R. Arredondo-Peter and E. Escamilla, A consensus sequence of plant hemoglobins. Plant Mol. Biol. Rep. 9 (1991), pp. 195-207.

25. C.A. Appleby, V. Bogusz, E.S. Dennis and W.J. Peacock, A role for hemoglobin in all plant roots?. Plant Cell Environ. 11 (1988), pp. 359-367.

26. M. Hargrove, E.A. Brucker, B. Stec, G. Sarath, R. Arredondo-Peter, R.V. Klucas, J.S. Olson and G.N. Philips, Jr., Crystal structure of a non-symbiotic hemoglobin. Structure 8 (2000), pp. 1005-1014.

27. M.D. Goodman and M.S. Hargrove, Quaternary structure of rice nonsymbiotic hemoglobin. J. Biol. Chem. 276 (2001), pp. 6834-6839.

28. S.M.G. Duff, P.A. Guy, X. Nie, D.C. Durnin and R.D. Hill, Haemoglobin expression in germinating barley. Seed Sci. Res. 8 (1998), pp. 431-436.

29. V. Lira-Ruan, G. Sarath, R.V. Klucas and R. Arredondo-Peter, Synthesis of hemoglobins in rice (Oryza sativa var. Jackson) plants growing in normal and stress conditions. Plant Sci. 161 (2001), pp. 279-287.

30. R.D. Hill, What are hemoglobins doing in plants?. Can. J. Microbiol. 76 (1998), pp. 707-712. 